\title{
TOMÁS DE AQUINO Y LA RELACIÓN ENTRE FILOSOFÍA Y TEOLOGÍA: UNA INTERPRETACIÓN LITERAL DE LA SUMA DE TEOLOGÍA I, Q. 1, ART. 1
}

\author{
José María Felipe Mendoza* \\ doi:10.11144/Javeriana.uph35-70.arft
}

\begin{abstract}
RESUMEN
El presente estudio indaga la posición de Tomás de Aquino sobre la relación entre filosofía y teología sagrada o sacra doctrina, tal como ha sido expuesta en la Prima Pars, q. 1, a. 1, de la Suma de Teología. Esta distinción busca fijar los límites entre ambas disciplinas a partir de su relación con la antropología, en la medida en que el Aquinate comprende la filosofía como esencialmente natural y racional, y la sacra doctrina como aquella ciencia cuyo fundamento es la gratuidad de la fe.
\end{abstract}

Palabras clave: Tomás de Aquino; Suma de Teología; filosofía; ciencia

Universidad Nacional de Cuyo, Cuyo, Argentina - CONICET, Buenos Aires, Argentina.

Correo electrónico: josefelipemendoza@hotmail.com

Para citar este artículo: Mendoza, J. M. F. (2018). Tomás de Aquino y la relación entre filosofía y teología: una interpretación literal de la Suma de Teología I, Q. 1, Art. 1. Universitas Philosophica, 35(70), pp. 131-149. ISSN 0120-5323, ISSN en línea 2346-2426 doi:10.11144/Javeriana.uph3570.arft 


\title{
THOMAS AQUINAS \\ AND THE RELATIONSHIP BETWEEN PHILOSOPHY AND THEOLOGY: A LITERAL INTERPRETATION ON SUMMA THEOLOGICA I, Q. 1, A. 1
}

\author{
José María Felipe Mendoza
}

\begin{abstract}
This study examines Thomas Aquinas's view on the relationship between Philosophy and Sacred Theology, as described in the first part, q . 1 a. 1 of his Summa Theologica. That distinction intends to define the boundaries between those different disciplines by the way of their relation to Anthropology, inasmuch as Aquinas understands Philosophy as a natural and rational discipline and the Sacred Doctrine as a science grounded on the gratuitousness of faith.
\end{abstract}

Keywords: Thomas Aquinas; Summa Theologica; philosophy; science 


\section{La Prima pars de la Suma de Teología de Tomás de Aquino fue escrita} entre 1265 y 1268 . Tales años nos sitúan ante un Tomás cuyo pronunciamiento respecto de la relación entre las disciplinas filosóficas y la sacra doctrina revelan un maduro saber especulativo. Inmediatamente después, el Aquinate se abocó a comentar la Física aristotélica (1268-1269) y a pocos años de distancia redactó comentarios a otras obras de Aristóteles, tales como la Metafísica (1270-1271) o los Analiticos posteriores (1271-1272) (Torrell, 2002, pp. 365-367).

Torrell, en su prólogo de la Suma de Teología nos habla sobre la fama de este texto. Y, como quien se dispone a mencionar alguno de sus méritos, menciona de inmediato el profundo conocimiento que demuestra su autor de la tradición medieval, patrística y bíblica, y también de los principales filósofos griegos y latinos (Torrell, 2005, pp. ix, 71-85). A lo que naturalmente podríamos añadir la sutileza y rigurosidad de sus deducciones y, sin lugar a dudas, la admirable relación armónica entre fe y razón, puesta decididamente de manifiesto a lo largo de sus páginas (Torrell, 2002, p. 161-177).

La Suma de Teología exhibe, en lo que aquí nos interesa, la asunción del conocimiento racional por la fe. Es nuestro cometido abordar esta temática solamente en la Prima pars, q. 1. art. 1, mediante la relación entre filosofía y sacra doctrina. Para ello consideramos particularmente las brevísimas palabras del texto que prologa al artículo primero:

Y como nuestra intención es que se comprenda bajo algunos ciertos límites [esta cuestión], es necesario, en primer lugar, investigar sobre la misma sagrada doctrina qué es y a qué cosas se extiende. $Y$ con respecto a ello deben inquirirse diez cosas. La primera, sobre la necesidad de esta ciencia $(S \text {. Th., I, q. 1, pr.) })^{1}$.

La finalidad del texto señala la necesidad de la sacra doctrina. Esta será la tarea del artículo primero, cuyo título - generalmente añadido por las traducciones y recogido por la idea primordial del corpus - plantea si resulta necesaria otra doctrina, además de las disciplinas filosóficas, para la salvación del hombre. De esta manera la idea desplegada en el mentado artículo se anticipa en el prólogo de

1 "Et ut intentio nostra sub aliquibus certis limitibus comprehendatur, necessarium est primo investigare de ipsa sacra doctrina, qualis sit, et ad quae se extendat. Circa quae quaerenda sunt decem. Primo, de necessitate huius doctrinae". 
la misma Suma cuando aquí las palabras de Tomás ya adelantan la necesidad de la justificación de la existencia de la sacra doctrina y la insuficiencia de la filosofía para abarcar todo cuanto es. Veamos esto con mayor detenimiento.

En el proemio, Tomás adelanta con el término “intención” (intentio) la preocupación universal del quehacer del teólogo respecto de la aceptación de la fe, mediada, a la vez, por explicar, o el querer de la razón de hacer asequible un saber reservado a pocos y que es de suyo esotérico. Tal vocablo alude no solo al prólogo general de la obra destinado a los párvulos, para que estudien la fe católica con ánimo y esfuerzo, sino incluso explicita la tensión entre el saber humano y el saber divino advenido por fe. De allí que la noción de "intención” refleje para el Aquinate la necesidad de justificar la enseñanza de la teología cual sapientia superior respecto de la totalidad del saber doctrinal que representa la filosofía.

En relación con esto último el texto claramente dice: "se comprende bajo algunos ciertos límites" (sub aliquibus certis limitibus comprehendatur). Tales palabras sintetizan la singularidad de la situación, porque de la solución a esta cuestión depende el equilibrio cristiano entre fe y razón. Sin embargo, desde una perspectiva más amplia dicha temática no deja de señalar el problema medieval de carácter existencial -no reductible a un mero ejercicio académico- planteado por la dificultad real que tiene todo ser humano al dar cuenta de un saber de fe no penetrable completamente por la razón. Y ante ello notamos el incómodo problema de pronunciarse sobre el saber que le compete a la razón y sus límites.

Aquello que la razón puede conocer y cuáles son sus límites es explicable por la irrupción de la revelación en la historia de la humanidad. Este hecho significa que Dios se anonadó, haciéndose carne en su segunda persona como Jesucristo, para la salvación de los hombres. Y es desde esta óptica que Tomás piensa la relación entre filosofía y teología a partir de una clarificación de la filosofía según sí misma. Por lo tanto, la posición del Aquinate será esencialmente la comprensión de un teólogo respecto de la filosofía (Torrell, 2005, p. 21).

Se torna conveniente, además, afirmar que la razón de dicha relación entre ambas disciplinas es fundamentalmente teológica, pues late aquí la preocupación por la desmesura de la racionalidad humana que afirma siempre la autojustificación de la sabiduría humana y su independencia de la fe. Esto es lo que parece sugerir Tomás como trasfondo de la disputa en orden a una aceptación de la teología que emerge desde la gratuidad de la fe. Y es en definitiva por esta 
causa que la Suma de Teología comienza con un artículo destinado a persuadir al hombre sobre la legitimidad de la filosofía y su compatibilidad con respecto al mensaje revelado (Lafleur, 1994, pp. 45-65; Lafleur \& Carrier, 2005, pp. 261 294; Brasa Diez, 1979, pp. 87-109; Di Giacomo Z., 2013, pp. 65-90; Florido, 2014, pp. 121-146; Florido, 2010, pp. 135-145)2.

1. Un análisis de las objeciones: la Biblia y Aristóteles en defensa de la filosofía

LUEGO DE ESTA BREVE INTRODUCCIÓN, el artículo 1 presenta dos objeciones, un sed contra y el corpus. El artículo es sumamente breve y sin embargo tiene una importancia decisiva. Para comprender en qué reside su relevancia, consideremos detenidamente cada una de las palabras de Tomás. El primer argumento dice:

Ante la primera se procede así. Parece que no es necesario, además de las disciplinas filosóficas, tener otra doctrina. Pues el hombre no debería atender a aquellas razones que están sobre él, según aquello de Ec. 3, 22: "no investigues lo que te es superior". Pero aquellas cosas que están bajo la razón son tratadas con suficiencia en las disciplinas filosóficas. Por lo tanto, parece superfluo que haya otra doctrina además de las disciplinas filosóficas $(S$. Th., I, q. 1 , art. 1 , arg. 1$)^{3}$.

Las objeciones suelen comenzar dialécticamente. Se presenta una opinión bien fundada que contradiga la importancia de la tesis central que busca sostenerse. En este caso se otorga credibilidad filosófica a una suerte de conocimientos

2 La preocupación de Tomás de justificar la necesidad de la sacra doctrina propiamente como ciencia tiene por detrás el problema de la Facultad de Artes parisina y sus programas sobre la división de las ciencias de índole aristotélica. En el mismo escenario empiezan a cobrar fuerza las advertencias y finalmente las condenas a determinadas doctrinas consideradas peligrosas u opuestas a la fe, como es el caso de la doble verdad de raíz averroista. Luego, atender a las objeciones de la Prima pars de la Suma nos revela el clima general del pensamiento de la época.

3 “Ad primum sic proceditur. Videtur quod non sit necessarium, praeter philosophicas disciplinas, aliam doctrinam haberi. Ad ea enim quae supra rationem sunt, homo non debet conari, secundum illud Eccli. III, altiora te ne quaesieris. Sed ea quae rationi subduntur, sufficienter traduntur in philosophicis disciplinis.Superfluum igitur videtur, praeter philosophicas disciplinas, aliam doctrinam haberi". 
implícitos que aparecen mínimamente desplegados por medio de la argumentación que sigue a la tesis central. Y así, cuando en la Suma de Teología Tomás expresa que "parece que no es necesario", indica un universo de disciplinas cuyas doctrinas dicen con plena certeza lo que afirma explícitamente la tesis del argumento, a saber, la autosuficiencia de las disciplinas filosóficas. Mas lo que no dice de modo directo es esto: cuáles son tales disciplinas y qué afirman como doctrina (Lohrs, 1996, pp. 3-15).

Sin embargo, ello no invalida la comprensión plena de la objeción. Las disciplinas filosóficas contienen bajo sí la totalidad del saber, y dicho conocimiento es rigurosamente demostrativo. Las doctrinas aquí sostenidas y defendidas gozan de demostraciones ciertas y verdaderas, y provienen exclusivamente del ejercicio de la razón, en tanto y en cuanto se excluye la fe. De lo contrario, no habría autosuficiencia de la filosofía, sino opinión indebidamente argumentada, y así se justificaría la existencia de otra doctrina. Ahora bien, a esta tesis la objeción añade una razón persuasiva. Se dice, por un lado, que la filosofía no necesita en modo alguno de la fe, por lo que podría interpretarse como paradoja, en tanto el argumento sobre el carácter innecesario de la fe proviene de un argumento de fe.

La objeción distingue dos ámbitos: la naturaleza creada y Dios. Y según ello, no habría una completa exclusión de Dios de la mente humana. Tampoco un incipiente ateísmo, según la cultura medieval en general y según la objeción en particular. Habría más bien una creencia en Dios en lo que atañe al orden de la fe y de las costumbres. De esta manera, lo que aparece como trasfondo indica simultáneamente la creencia en Dios y su incompetencia con respecto al ámbito científico. Y este desdoblamiento aquí provocado significa que quien ejerce como filósofo puede creer en Dios, pero no puede inmiscuirlo en su enseñanza, en su doctrina, o en su reflexión científica. Basta el conocimiento que otorga la filosofía para comprender toda la naturaleza. Dios quedaría reservado para un ámbito personal, social y cultural, pero no para la ciencia.

Por una parte, se entiende que la filosofía es saber demostrativo respecto de la totalidad de la naturaleza. Por la otra, se sostiene que Dios creó el mundo y que ello es competencia de la fe. Tal situación muestra el límite entre filosofía y teología. La primera estudia la naturaleza creada, que es todo cuanto existe. En cambio, como doctrina de fe, la segunda carecería de sentido en el ámbito racional. Según dicha deducción, lo que subyace a la argumentación es la negación de la 
presencia de Dios en la naturaleza, en tanto y en cuanto ella no daría testimonio del Creador, sino de sí misma, desligada por completo de su causa, rompiéndose así la relación entre Creador y creatura.

La exclusión de la fe, habíamos mencionado, provenía de un argumento de fe, según aquella cita de Ec. 3, 22. En efecto, recordemos que Dios le dijo al hombre que no correspondía investigar lo que le era superior. En este contexto tal sentencia justificaría, por una parte, la exclusión de la filosofía respecto de la fe y, por otra, la afirmación de que la filosofía investiga la totalidad de la naturaleza. Se aprecia también aquí la reducción de la noción de naturaleza, porque señala lo orgánico e inorgánico creado por Dios, no a Dios mismo. Y según esta tesitura, las disciplinas filosóficas serán aquellas que estudien tales ámbitos. De esta manera se cierra magistralmente el argumento. No es que el hombre no quiera conocer a Dios, sino que Dios no lo ha permitido. No hay entonces soberbia, sino obediencia y humildad. El hombre sigue el mandato divino de conocer todo cuanto existe, hallando así la filosofía una justificación externa y superior a sus fuerzas. Y por ello concluye diciendo que es superfluo que exista otra doctrina aparte de la filosofía. Hasta aquí la objeción. La respuesta dice:

A la primera corresponde decir que, aunque haya cosas que sean más altas para el hombre según el conocimiento y no sean adquiridas por el hombre mediante la razón, empero lo son como reveladas por Dios, debiendo ser aceptadas por la fe. De allí que aquel texto añada: muchas cosas que están por encima del hombre le han sido enseñadas. $\mathrm{Y}$ en estas cosas consiste la Sagrada Doctrina (S. Th., I, q. 1, art. 1, ad. 1) .

La respuesta de Tomás asume en parte la objeción. No niega que las disciplinas filosóficas estudien e investiguen toda la naturaleza creada, pero introduce una diferencia. La filosofía no considera todo cuanto es, sino todo cuanto es creado y lo material. Esta división de ámbitos permite la incorporación de la sagrada doctrina con un contenido preciso y con un modo de abordarlo. La filosofía adquiere conocimiento de la naturaleza por medio de la razón. Y lo que es

4 "Ad primum ergo dicendum quod, licet ea quae sunt altiora hominis cognitione, non sint ab homine per rationem inquirenda, sunt tamen, a Deo revelata, suscipienda per fidem. Unde et ibidem subditur, plurima supra sensum hominum ostensa sunt tibi. Et in huiusmodi sacra doctrina consistit". 
superior a la razón humana -lo que, según esto, sería incognoscible- es revelado por Dios.

El hombre estudia todo cuanto existe, es decir, la naturaleza orgánica e inorgánica. Y todo ello lo conoce por sus propias fuerzas. En cambio, no debiendo aceptar nada que esté por encima de la razón, a riesgo de que sea inexistente, acepta lo que le es superior por revelación. Este es el centro del argumento que resuelve la primera objeción. Para que el hombre acepte aquello que le es superior, la revelación de algún modo tiene que guardar relación con la naturaleza y con la filosofía como disciplina que la investiga. Y he aquí el enlace: Dios se anonadó haciéndose hombre. De esta manera, dicha realidad es el punto de unión entre la filosofía y la sagrada doctrina. Ahora bien, la filosofía estudia todo cuanto existe y, sin embargo, ello no significa lo mismo que la mera realidad creada. Con la encarnación, entre todo lo que existe y el ámbito de estudio propio de la filosofía está también Dios Hijo. A lo revelado, dice Tomás, corresponde que sea aceptado. Y el contenido definitivo es la encarnación del Hijo para la salvación de los hombres.

Según el texto, la teología proviene de lo alto y la filosofía de nosotros. El origen es diferente y lo que se cuestionó en la objeción no es tanto el principio, sino el justo medio del encuentro entre ambas en orden a incluir la sagrada doctrina como disciplina. Por esa razón, el principio tiene cierta injerencia, pues si la filosofía proviene del hombre, entonces lo que no comience en él en tanto principio no tendrá lugar, al menos en las enseñanzas doctrinales. Empero, la aceptación de la sagrada doctrina para su completa inteligibilidad proviene de la fe. Y una vez aceptada esta premisa, la sagrada doctrina sería disciplina de pleno derecho.

Ahora bien, ante la inclusión efectiva de la sagrada doctrina como disciplina se advierte que su fundamento es diferente. La filosofía y la sagrada doctrina se llaman disciplinas porque hay en ellas una doctrina dispuesta a ser enseñada y transmitida. Pero mientras que la filosofía procede con fundamentación en el esse creatural, la sagrada doctrina lo hace con fundamentación en la palabra bíblica. De esta manera, la noción de disciplina se vuelve análoga porque, si de suyo es propia de la enseñanza de la filosofía, ahora también implica la transmisión de la fe.

Consideremos ahora la siguiente objeción, que dice:

Además [toda] doctrina no puede ser sino del ente, pues nada se sabe si no es verdadero, lo cual se convierte con el ente. Pero todos los entes son tratados 
en las disciplinas filosóficas, y también Dios, y de ahí que alguna parte de la filosofía se diga teología o ciencia divina, como se evidencia por el filósofo en el VI libro de la Metafísica. Por ello no fue necesario, además de las disciplinas filosóficas, tener otra doctrina (S. Th., I, q. 1, a. 1, arg. 2$)^{5}$.

Una primera lectura manifiesta la inclusión de Dios en la filosofía. Pero también se nota que en la primera objeción se comprendía que Dios, sujeto absoluto de la sagrada doctrina, no era competencia de la filosofía. De ahí que la cita bíblica se refiera a no investigar lo que es superior al hombre. Hasta aquella objeción el límite de la filosofía era la comprensión de la naturaleza, pero ahora el límite se ha extendido. Si la respuesta de Tomás a la primera objeción le otorgaba lugar a la sacra doctrina como disciplina, entonces esta segunda objeción -coincidiendo en parte con la primera respuesta- acepta la sagrada doctrina como disciplina bajo una resignificación con la que Tomás no estaría del todo de acuerdo. Ahora Dios es parte del estudio de la filosofía, cuya disciplina lleva por nombre teología o ciencia divina.

La enseñanza, dice el texto, es siempre sobre los entes. La filosofía se dividirá, en consecuencia, según los tipos de entes. Algunas partes de la filosofía, o lo que es lo mismo, algunas de las disciplinas del corpus completo del saber, estudiarán los entes inorgánicos y otros los orgánicos, según sus especificaciones y diferencias. Y ahora, entre los entes, se menciona a Dios. De ese modo, la totalidad de la filosofía no se restringe a las disciplinas físicas o matemáticas, porque se expande a la teología o filosofía divina por tratar acerca de Dios (Lorenz Daiber, 19992000, pp. 143-153). Y de aquí la convergencia terminológica entre las expresiones "teología” y "ciencia divina” o "filosofía divina”. Todas ellas expresan que el saber sobre lo divino puede ser enseñado como parte de la filosofía y que, por ello, es explicable por medio de la razón.

El argumento es concluyente. En la objeción se menciona la teoría de los trascendentales y la consecuente convertibilidad entre el verum y el ens. Y esto importa, porque su convertibilidad aparece decididamente como el fundamento natural

5 "Praeterea, doctrina non potest esse nisi de ente, nibil enim scitur nisi verum, quod cum ente convertitur. Sed de omnibus entibus tractatur in philosophicis disciplinis, et etiam de Deo, unde quaedam pars philosophiae dicitur theologia, sive scientia divina, ut patet per philosophum in VI Metaphys. Non fuit igitur necessarium, praeter philosophicas disciplinas, aliam doctrinam haberi". 
y la fuente desde la cual la razón humana conoce y piensa, cuya consecuencia es la certeza del razonamiento. La inclusión de la ciencia divina, como parte integrante de la filosofía, también indica que esta disciplina se despliega pronunciándose con verdad acerca de Dios. Por ello no sería necesaria otra doctrina.

Si antes la filosofía no contemplaba la posibilidad de un estudio racional sobre Dios, ahora lo acepta, excluyendo, sin embargo, al Dios de la fe, el cual, diríamos, sigue siendo parte de la creencia personal o cultural, pero no estrictamente científica. Al preguntarnos por cuál es la consecuencia de este planteamiento, entendemos que aquí se expresa la escisión entre una comprensión de Dios según la revelación y la existencia de una filosofía que estudia a Dios como ente verdadero, deduciendo cuáles son sus características reales y científicas. Es decir, parece que Dios entraría bajo la consideración de la razón natural.

La objeción es, para la mente de un medieval como Tomás de Aquino, ciertamente destructiva. La separación entre el Dios revelado de la fe y el Dios para la filosofía, si bien no es un constructo (porque es un ente real y verdadero, no devenido del mero ingenio o de la imaginación), es inaceptable, porque eventualmente conduciría a fuertes equívocos respecto de quién es Dios. Detengámonos ahora en la respuesta.

A la segunda corresponde afirmar que la diversa razón de lo cognoscible lleva a la diversidad de las ciencias. En efecto, la misma conclusión demuestra el astrónomo y el [filósofo] natural, como por ejemplo, que la tierra es redonda; pero el astrónomo por medio de la matemática, a saber, por la materia abstracta, y en cambio el filósofo natural, por medio de la consideración de la materia. De donde nada prohíbe que sobre las mismas cosas traten (i) las disciplinas filosóficas según que son cognoscibles por la luz natural de la razón, y (ii) otra ciencia, según que se conoce por la luz de la divina revelación. De ahí que la teología, que pertenece a la sagrada doctrina, difiere según el género de aquella otra teología que se coloca como parte de la filosofía $(S$. Th., I, q. 1, a. 1, ad. 2) .

6 "Ad secundum dicendum quod diversa ratio cognoscibilis diversitatem scientiarum inducit. Eandem enim conclusionem demonstrat astrologus et naturalis, puta quod terra est rotunda, sed astrologus per medium mathematicum, idest a materia abstractum; naturalis autem per medium circa materiam consideratum. Unde nibil probibet de eisdem rebus, de quibus philosophicae disciplinae tractant 
Hasta el momento las expresiones "filosofía" y "ciencia" parecen intercambiables. Las disciplinas filosóficas tienen ahora una razón que explica su pluralidad, y ella no es otra que "la diversa razón de lo cognoscible", lo cual referencia, inmediatamente, que los entes tienen una forma de cognoscibilidad y que, consecuentemente, pueden ser y son conocidos por los hombres. Las razones o formas son llamadas también especies y dicen qué entes estamos conociendo. De este modo, la filosofía se diversifica según los entes reales, o con sustento en la realidad, y no según los entes de razón.

Ahora bien, el texto continúa señalando, a partir de la previa diferencia, la mutua relación de dos disciplinas según el ente considerado. Pues la diversidad de las partes de la filosofía no obstaculiza su relación armónica entre distintas áreas del saber ni la utilización de investigaciones de una en otra diferente. Esto dice Tomás con el ejemplo de la astronomía y la física. Y este ejemplo es útil por analogía en orden a la teología.

Una cuestión es la división de la filosofía en sus partes o disciplinas, como la matemática y la física, y otra la división de la filosofía y su relación con la teología. En el caso de la filosofía se comprende que todas sus partes se distingan -esto es, que no se reduzcan por univocidad a una sola- y, sobre la base de esa distinción, que se presten mutua colaboración. Esto es comprensible por el hecho de que todas son disciplinas filosóficas fundadas sobre los entes cognoscibles por la razón. En cambio, en la teología esta lógica del razonamiento no es tan evidente, excepto que, a Dios, sujeto absoluto de la teología, pueda referenciárselo de dos maneras. Por un lado, Tomás acepta que pueda estudiarse a Dios según la razón, bajo los nombres de filosofía divina, ciencia divina o teología. Mas no acepta que sea el único modo, en virtud de los peligros considerados anteriormente. De ahí la necesidad de distinguir dos teologías. Por una parte, la teología filosófica que estudia a Dios según la luz natural de la razón y, por otra, la teología como parte integrante de la sacra doctrina, cuyo conocimiento proviene de la luz divina de la revelación. Empero, la necesidad de colocar aquí una teología no enteramente filosófica señala

secundum quod sunt cognoscibilia lumine naturalis rationis, et aliam scientiam tractare secundum quod cognoscuntur lumine divinae revelationis. Unde theologia quae ad sacram doctrinam pertinet, differt secundum genus ab illa theologia quae pars philosophiae ponitur". 
principalmente su superioridad con respecto a aquella filosófica, para juzgarla, orientarla, corregirla y facilitarle su comprensión de los misterios de la revelación.

No hay que comprender simplemente que Tomás reconoce la existencia de dos teologías. De un lado, la teología como sacra doctrina; de otro, como ciencia filosófica. Analicemos ello con mayor detenimiento. En primer lugar, notamos que esta diferencia proviene del principio considerado. El primero es la fe y el segundo la razón. En su mutua relación no debemos ver otra cosa que la injerencia de la sacra doctrina en la teología filosófica. Y esta es la analogía acentuada por Tomás. Así como ocurre con la matemática y la física, así con la teología filosófica y la teología sagrada.

En segundo lugar, y como deducción de esta primera parte, se evidencia que el Aquinate no adjunta la teología sacra a la filosófica sin más. Su razón es que, una vez distinguidas, la primera de ellas pueda pronunciarse sobre el saber de la teología filosófica, y así el mapa de ciencias se dividirá en las disciplinas filosóficas y en la disciplina de la teología sacra. Y en esta división la sacra doctrina se establece como ciencia superior a las demás, incluida la teología que forma parte de la filosofía.

\section{Asunción y legitimidad de la filosofía en orden a la reflexión teológica}

DespuéS DE las objeciones en las dUe la filosofía se posiciona como saber universal, a causa de su conocimiento exhaustivo sobre la creación y sobre Dios, consideremos ahora las palabas del sed contra:

Pero contra esto se dice en II, Tim. 3, 16: Toda la Escritura, divinamente inspirada, es útil para enseñar, argumentar, corregir, y formar para la justicia. Sin embargo la Escritura, que es divinamente inspirada, no pertenece a las disciplinas filosóficas, que son descubiertas según la razón humana. Por ello es útil, además de las disciplinas filosóficas, que haya otra ciencia divinamente inspirada (S. Th., I, q. 1, a. 1, s.c. $)^{7}$.

7 "Sed contra est quod dicitur II ad Tim. III, omnis Scriptura divinitus inspirata utilis est ad docendum, ad arguendum, ad corripiendum, ad erudiendum ad iustitiam. Scriptura autem divinitus inspirata 
Recordemos que ambas objeciones tienen en común la inaceptabilidad de la sacra doctrina. La primera justifica su rechazo desde la Escritura y la segunda desde Aristóteles. Dejando de lado las diferencias entre tales objeciones, el sed contra arremete contra ellas con verdadera fuerza persuasiva. Si las disciplinas filosóficas son tales en virtud de la doctrina profesada, que es debidamente fundamentada, la sacra doctrina es disciplina porque también cumple con tales condiciones. Su verdadero fundamento es Dios y lo que Él dijo de sí -según aquello de "divinamente inspirada"-. Y por esta condición de disciplina, la filosofía tiene verdaderamente la autoridad para enseñar, ya argumentando algún saber o corrigiendo algún error. Y si ello es así, mayormente lo será para la sacra doctrina que se sostiene en la imposibilidad de que Dios se equivoque o contradiga. De esta manera la autoridad de la sacra doctrina rige sobre todo saber filosófico de la misma manera que la filosofía sobre algún saber que le competa. Ella enseña, argumenta y corrige el cuerpo del saber filosófico en su totalidad.

Según lo anterior, parecería que el sed contra basta por sí mismo con respecto a las objeciones. Sin embargo, no logra mostrar con precisión de qué manera la filosofía es útil a la teología. Y por ello, si bien el esquema de Tomás sobre el orden de las ciencias es comprensible, sigue pareciendo que el enlace entre la filosofía y la teología es, en cierto sentido, forzado, pues la claridad de su relación ha sido mostrada, de momento, solo en forma genérica. Por lo tanto, es necesario que el principio del saber esté en la misma filosofía. Y esta es la respuesta definitiva de Tomás de Aquino en el corpus, que dice:

Respondo diciendo que fue necesario para la salvación humana que hubiera cierta doctrina según la revelación divina, además de las disciplinas filosóficas, que sea descubierta por la razón humana. En primer lugar, sin duda, porque el hombre se ordena a Dios como a cierto fin que excede la comprensión de la razón, según aquello de Isaías 64, 4: ¡Oh Dios, ningún ojo vio lo que preparaste para los que te aman! Sin embargo conviene que el fin sea pre-conocido por los hombres, quienes se ordenan al fin según sus intenciones y acciones. De donde fue necesario para la salvación del hombre que en

non pertinet ad philosophicas disciplinas, quae sunt secundum rationem humanam inventae. Utile igitur est, praeter philosophicas disciplinas, esse aliam scientiam divinitus inspiratam". 
cierto modo aquello se hiciera evidente por revelación divina, que excede la razón humana. Y también, para que puedan investigarse por la razón humana aquellas cosas referidas a Dios, fue necesario para el hombre instruirse en la revelación divina. Porque la verdad sobre Dios, fue descubierta por pocos por medio de la razón, y por largo tiempo y con mezcla de numerosos errores se mostró al hombre, y, sin embargo, del conocimiento de dicha verdad depende toda la salvación del hombre que está en Dios. Por ello, para que la salvación llegara a los hombres de modo más conveniente y seguro, fue necesario que se instruyeran sobre las cosas divinas por la divina revelación. Y por ello fue necesario que, además de las disciplinas filosóficas, descubiertas por la razón, hubiera por revelación una sagrada doctrina $(S \text {. Th., I, q. 1, a. 1, co. })^{8}$.

La respuesta comienza con una afirmación propia de la sacra doctrina. Vemos que la finalidad de todo saber debe guardar relación con el destino del hombre. Si las objeciones y el sed contra giran en torno a la importancia de que la teología sacra sea ciencia (Celada Luengo, 2010, pp. 33-62), es porque las ciencias deben a su manera dar cuenta de la finalidad del hombre. Y así, lo que la persona piense sobre los conocimientos adquiridos es esencial para su salvación.

Aquí se evidencia el enlace entre el principio y origen de la sacra doctrina y el hombre que la descubre. Lo primero atañe a la revelación, cuyo fin está en la salvación de la humanidad. En cambio, lo segundo referencia la disposición humana para recibir el mensaje evangélico. Y ello en el ámbito de las ciencias significa que la sacra doctrina requiere, para ser recibida en su totalidad, la condición

8 "Respondeo dicendum quod necessarium fuit ad humanam salutem, esse doctrinam quandam secundum revelationem divinam, praeterphilosophicas disciplinas, quae ratione humana investigantur. Primo quidem, quia homo ordinatur ad Deum sicut ad quendam finem qui comprehensionem rationis excedit, secundum illud Isaiae LXIV, oculus non vidit Deus absque te, quae praeparasti diligentibus te. Finem autem oportet esse praecognitum hominibus, qui suas intentiones et actiones debent ordinare in finem. Unde necessarium fuit homini ad salutem, quod ei nota fierent quaedam per revelationem divinam, quae rationem humanam excedunt. Ad ea etiam quae de Deo ratione humana investigari possunt, necessarium fuit hominem instrui revelatione divina. Quia veritas de Deo, per rationem investigata, a paucis, et per longum tempus, et cum admixtione multorum errorum, homini proveniret, a cuius tamen veritatis cognitione dependet tota hominis salus, quae in Deo est. Ut igitur salus hominibus et convenientius et certius proveniat, necessarium fuit quod de divinis per divinam revelationem instruantur. Necessarium igitur fuit, praeter philosophicas disciplinas, quae per rationem investigantur, sacram doctrinam per revelationem haberi." 
humana de una vida dispuesta. Dicha disposición se traduce como la preparación mediante las disciplinas filosóficas, pues ellas nos dirigen y preparan para la libre recepción de la fe en la medida que Dios así lo quiera. De ahí que la noción de descubrimiento de la sacra doctrina no equivalga a la de la filosofía en general. En filosofía, "descubrir" supone que la razón humana aprehende primero y principalmente los entes naturales por medio de la razón (Herrera, 2014, pp. 230242). En la sacra doctrina, "descubrir" supone que la razón humana aprehende fundamentalmente por la fe. Es ella la que ilumina la razón y quien la conduce hacia la vivencia del misterio de la revelación. Así se armonizan ambas disciplinas, filosofía y teología sagrada, en la vivencia íntegra de la persona.

La respuesta completa de Tomás se manifiesta en dos planos: por un lado, la antropología, y por el otro, la revelación. La coherencia de ambos en la vida también debe quedar reflejada en las ciencias. De ahí que la subordinación de todas las disciplinas filosóficas a la teología sagrada y su adecuada interrelación transparente al mismo tiempo un universo ordenado y una vida en tensión a Dios mediante su conocimiento. Ambos planos importan. La filosofía, cuyo saber expresa un conocimiento cierto y armónico entre las disciplinas que la conforman, es, en tanto atañe al ser humano, principio incuestionable del saber. La fe respecto de las Escrituras, fundamento de la sacra doctrina, es un obsequio divino que no elimina, sino que exige, cierto despliegue de las disciplinas filosóficas.

La filosofía, en cuanto se entiende como saber de las causas descubiertas por la razón respecto de la contemplación e indagación de la naturaleza, es primera o anterior respecto de la sacra doctrina. Esta prioridad quoad nos, al igual que la sacra doctrina, se ordena a Dios. Ambos saberes lo hacen de diferente manera. En el caso del saber filosófico se alcanza a Dios de un modo difuso y oscuro, según la afirmación que dice "excede la comprensión de la razón" y sin embargo es "pre-conocido por los hombres”. Entre ambas notas aparecen dos características: i) Dios nos espera con infinito amor; ii) conquistamos tal fin según nuestras intenciones y acciones. La primera no solo es una exigencia de la sacra doctrina, sino que, incluso, trasladada al saber filosófico, se transforma en un puente entre aquellas dos notas. A Dios lo conocemos in via de modo oscuro e incierto. Y en cuanto tal decimos que la incomprensión de la razón no es negación o desconocimiento absoluto. Es tensión cierta hacia Dios, aunque incierto es el camino. La vivencia del amor arroja luz sobre dicha tensión, porque nos orienta hacia 
el mismo Dios que es amor. Y si esta vivencia del amor abraza las intenciones y se concretiza en las acciones, entonces in via nos dirigimos a Dios. De ahí que entre las ciencias exista un fin personal que es transversal a todo saber y que es justamente el amor a Dios. Este fin se vuelve ciencia cuando aquello que in via aparecía como oscuro entre las disciplinas filosóficas, ahora, en la sacra doctrina, se aclara. De este modo, la claridad del fin personal, que es Dios, solo se da en la sacra doctrina; en razón de ello el texto dice que "fue necesario para la salvación del hombre que en cierto modo aquello se hiciera evidente por revelación divina, que excede la razón humana”.

Hasta aquí el texto cimienta las bases de un saber acerca de Dios. Por una parte, la prioridad quoad nos de la filosofía (Sanz, 2004, pp. 911-929), cuyas notas serían (i) su independencia tensional respecto de la teología sagrada en virtud de la gratuidad de la fe, (ii) su apertura a la misma y (iii) su indigencia en la comprensión del ser divino. De todas ellas se sigue la libre necesidad de la sacra doctrina. A partir de este punto la respuesta del Aquinate profundiza en algunos matices del conocimiento divino. Si por medio de la filosofía o ciencia divina el hombre alcanza a tener un conocimiento de Dios real y oscuro, por el asentimiento a la revelación -y la comprensión de que ella es verdadera ciencia sagrada- ahora es posible que la oscuridad de la razón desaparezca en parte. En la medida en que nuestra condición sea in via, la oscuridad de la razón será doble, por la ausencia de la fe, esa oscuridad será mayor; pero por la luz de la fe, será menor. Empero, cuando nuestra condición humana sea in patria, conoceremos sin velo.

Esta capacidad de la razón para profundizar el misterio divino in via solo es posible por la revelación que sienta las bases para una mejor y mayor comprensión de Dios. Esta es la diferencia respecto de la ciencia de la teología. Ellas tienen el mismo subiectum, que es Dios, y un género diferente según el origen. La teología filosófica alcanza un saber racional respecto del ser divino y que es caracterizado así: porque la verdad sobre Dios fue descubierta por pocos por medio de la razón, y por largo tiempo y con mezcla de numerosos errores se mostró al hombre. En cambio, la teología sacra -superior a la filosófica y no alcanzada simplemente por medio de la razón, sino ayudada por la fe- dirige y corrige las imperfecciones del conocimiento racional de Dios, porque en ella descansa toda la salvación del género humano. Esto es, a las afirmaciones conclusivas de la teología filosófica, la sacra doctrina las juzga con asentimiento, o bien las matiza o 
rechaza. En todos estos casos la fe se comporta como directriz lumínica respecto de un intelecto que, en estas condiciones, se presenta más sombrío.

Dicha afirmación previa sobre la responsabilidad que le cabe a la sacra doctrina es en definitiva la verdadera finalidad de esta ciencia. Y ese es el norte que guía este artículo de la Suma en particular. De esta manera concluye el Aquinate su reflexión, al afirmar la necesidad de obtener cierta certeza respecto del destino del hombre, cuando enuncia: "fue necesario que, además de las disciplinas filosóficas, descubiertas por la razón, hubiera por revelación una sagrada doctrina”.

\section{Consideraciones finales}

EN TORNO A LA RELACIÓN ENTRE FILOSOFÍA Y TEOLOGía hemos querido ofrecer una reflexión literal de un texto clave como el que aquí tratamos. Antes que abordar esta temática en forma genérica y transversal, buscamos repensar a Tomás de Aquino de un modo más ceñido según esta obra. La Suma de Teología, obra prototípica del saber escolástico a juicio general de la historia de la filosofía, ha sido la ocasión concreta para mostrar la vitalidad del pensar tomístico en torno a esta problemática de carácter transhistórico.

El alcance de la filosofía en la teología configura este último saber de modo particular en dos momentos trabados armónicamente. La teología, mediada por la fe, trataría en un primer momento sobre Dios, haciendo las veces de principio y fundamento de este saber. Su segundo momento es aquel que le corresponde a la razón. Y así el momento racional, sujeto a aquel de la fe, es el principio natural por el cual buscamos comprenderlo.

El primer momento referencia la sacra doctrina; el segundo, la metafísica o teología natural y filosófica. Empero, según lo hasta aquí expuesto, tales momentos no son partes diferentes y separadas de suyo, como si fuesen dos ciencias con subiecta diversos, sino una misma ciencia que trata sobre Dios desde dos géneros diferentes. Por un lado, el antropológico, porque se aborda a Dios, subiectum de la teología, desde la razón; y por el otro, el divino, porque el hombre se vuelve exégeta de la Escritura según la fe, en tanto orienta el conocimiento de la revelación.

Por lo demás, hacemos notar la resignificación operada en la noción de filosofía. Su límite es la libertad de la razón (natural) sobre la naturaleza. La fe incorpora, asume, atraviesa y dirige el pensar filosófico en lo que respecta a Dios y la 
creación, expandiendo el horizonte de comprensión racional. De esta manera la filosofía (i) no se opone a la teología, (ii) le queda sujeta interiormente (porque bajo cierto respecto le es constitutivo su pensar), y (iii) no se opone a la fe y se halla presupuesta y en tensión hacia aquella.

Por la filosofía se contempla a Dios imperfectamente e in via, en tanto este saber señala un conocimiento racional sin fe y expuesto a la trascendencia. En cambio, por el conocimiento infuso de la fe, se señala la contemplación de Dios de modo más perfecto que el filosófico, por cuanto culmina en la vida sobrenatural in patria ante Dios.

\section{Referencias}

Brasa Diez, M. (1979). La filosofía en el mundo de Tomás de Aquino. Studium, XIX(1), 87-109.

Celada Luengo, G. (2010). El aprecio de santo Tomás por la sagrada doctrina como ciencia. Ciencia Tomista, 137(441), 33-62.

Di Giacomo Z., M. (2013). Santo Tomás de Aquino y Sigerio de Brabante: La duplex veritas como nuncio de una secularización en ciernes. Studia Gilsoniana, (2), 65-90.

Florido, F. L. (2014). La censura académica y los límites de la libertad en la universidad medieval. En torno a las consecuencias de la condena de 1277. Ciencia Tomista, 141(453), 121-146.

Florido, F. L. (2010). Las filosofias en la Edad Media. Crisis, controversias y condenas. Madrid: Biblioteca Nueva.

Herrera, J. J. (2014). El progreso de la razón filosófica en Tomás de Aquino: la indagación sobre el origen de las cosas. En: D’Amico, C. \& Tursi, A. (Eds.). Studium Philosophiae. Textos en homenaje a Silvia Magnavacca (pp. 230242). Buenos Aires: Rhesis.

Lafleur, C. (1994). Scientia et ars dans les introductions à la philosophie des maîtres ès arts de l'Université de Paris au XIIIe siècle. Miscellanea Mediaevalia, 22(1), 45-65.

Lafleur, C. \& Carrier, J. (2005). Dieu, la théologie et la métaphysique au milieu $\mathrm{du}$ XIIIe siècle selon des textes épistémologiques artiens et thomasiens. Revue des Sciences philosophiques et théologiques, 89, 261-294. 
Lohrs, L. (1996). Del aristotelismo medieval al aristotelismo renacentista. La transformación de la división aristotélica de las ciencias especulativas en el s. XVI. Patristica et Mediaevalia, XVII, 3-15.

Lorenz Daiber, D. (1999-2000). La teoría aristotélica de las ciencias y su relación con la antropología y la teología de Santo Tomás. Revista Philosophica, 22-23, 143-153.

Sanz, S. (2004). Fe y razón ante el misterio de la Trinidad creadora según Santo Tomás. Scripta Theologica, 36, 911-929.

Torrell, J. P. (2002). Iniciación a Tomás de Aquino: su persona y su obra. Pamplona: Eunsa.

Torrell, J. P. (2005). Aquinas's Summa. Background, Structure and Reception. Washington, D.C.: The Catholic University of America Press. 